\title{
A Mutation in the Propeptide of Factor IX Leads to Warfarin Sensitivity by a Novel Mechanism
}

\author{
Kirk Chu, ${ }^{\star}$ Sheue-Mei Wu, ${ }^{\ddagger}$ Tom Stanley, ${ }^{\ddagger}$ Darrel W. Stafford, ${ }^{\ddagger}$ and Katherine A. High* \\ *Department of Pediatrics and Pathology, University of Pennsylvania and Children's Hospital of Philadelphia, Philadelphia, \\ Pennsylvania 19104; and ${ }^{\ddagger}$ Department of Biology, University of North Carolina at Chapel Hill, Chapel Hill, North Carolina 27599
}

\begin{abstract}
The propeptide sequences of the vitamin $\mathrm{K}$-dependent clotting factors serve as a recognition site for the enzyme $\gamma$-glutamylcarboxylase, which catalyzes the carboxylation of glutamic acid residues at the $\mathrm{NH}_{2}$ terminus of the mature protein. We describe a mutation in the propeptide of Factor IX that results in warfarin sensitivity because of reduced affinity of the carboxylase for the Factor IX precursor. The proband has a Factor IX activity level of $>100 \%$ off warfarin and $<1 \%$ on warfarin, at a point where other vitamin K-dependent factors were at $30-40 \%$ activity levels. Direct sequence analysis of amplified genomic DNA from all eight exons and exon-intron junctions showed a single guanosine $\rightarrow$ adenosine transition at nucleotide 6346 resulting in an alanine to threonine change at residue -10 in the propeptide. To define the mechanism by which the mutation resulted in warfarin sensitivity, we analyzed wild-type and mutant recombinant peptides in an in vitro carboxylation reaction. The peptides that were analyzed included the wild-type sequence, the Ala-10 $\rightarrow$ Thr sequence, and Ala$10 \rightarrow \mathrm{Gly}$, a substitution based on the sequence in bone $\gamma$-carboxyglutamic acid protein. Measurement of $\mathrm{CO}_{2}$ incorporation at a range of peptide concentrations yielded a $V_{\max }$ of $343 \mathrm{cpm} / \mathrm{min} /$ reaction for the wild-type peptide, and $V_{\max }$ values of 638 and 726 for A-10T and A-10G respectively, a difference of only twofold. The $K_{\mathrm{m}}$ values, on the other hand, showed a 33-fold difference between wild-type and the variants, with a value of $0.29 \mu \mathrm{M}$ for wild-type, and 10.9 and $9.50 \mu \mathrm{M}$, respectively, for A-10T and A-10G. Similar kinetic experiments showed no substantial differences between wild-type and mutant peptides in kinetic parameters of the carboxylase-peptide complexes for reduced vitamin $\mathrm{K}$. We conclude that the major defect resulting from the Factor IX Ala-10 $\rightarrow$ Thr mutation is a reduction in affinity of the carboxylase for the mutant propeptide. These studies delineate a novel mechanism for warfarin sensitivity. In addition, the data may also explain the observation that bone Gla protein is more sensitive to warfarin than the coagula-
\end{abstract}

Address correspondence to Katherine A. High, M.D., 310A Abramson Research Center, 324 S. 34th Street, Philadelphia, PA 19104. Phone: 215-590-4521; FAX: 215-590-3660; E-mail: high@email. chop.edu Received for publication 26 March 1996 and accepted in revised form 17 July 1996.

J. Clin. Invest.

(c) The American Society for Clinical Investigation, Inc. 0021-9738/96/10/1619/07 \$2.00

Volume 98, Number 7, October 1996, 1619-1625 tion proteins. (J. Clin. Invest. 1996. 98:1619-1625.) Key words: Factor IX $\bullet$ vitamin $\mathrm{K} \cdot$ propeptide $\bullet \boldsymbol{\gamma}$-glutamylcarboxylase $\cdot$ warfarin sensitivity

\section{Introduction}

Vitamin K-dependent proteins include coagulation Factors IX, X, VII, and II (F.IX, F.X, F.VIII, and F.II) ${ }^{1}$ proteins C, S, and $\mathrm{Z}$, bone Gla protein, matrix Gla protein, and a newly discovered cell growth regulation protein, Gas6 (1). The biosynthesis of the vitamin $\mathrm{K}$-dependent proteins involves a complex series of posttranslational modifications. Among these, removal of the signal peptide and propeptide, $\mathrm{N}$ - and $\mathrm{O}$-linked glycosylation, hydroxylation of an asparate and in some cases, cleavage at internal basic residues are common features shared by other secreted proteins; however, $\gamma$-carboxylation is a unique posttranslational modification that is required for the biological activities of all the vitamin $\mathrm{K}$-dependent proteins. $\gamma$-Carboxylation, catalyzed by the enzyme $\gamma$-glutamylcarboxylase, occurs in the endoplasmic reticulum. In addition to the small substrates $\mathrm{CO}_{2}$ and $\mathrm{O}_{2}$, the carboxylase also requires vitamin $\mathrm{K}$ hydroquinone as a cofactor in the reaction (2). During carboxylation, vitamin $\mathrm{K}$ hydroquinone is converted into vitamin $\mathrm{K}$ epoxide. Regeneration of vitamin $\mathrm{K}$ is dependent on the enzyme vitamin $\mathrm{K}$ epoxide reductase, the key enzyme targeted by warfarin (Fig. 1). Thus, anticoagulation by warfarin indirectly inhibits carboxylase by blocking the regeneration of vitamin $\mathrm{K}$ hydroquinone.

A critical factor in the regulation of $\gamma$-carboxylation is the propeptide sequence of the vitamin $\mathrm{K}$-dependent protein. Jorgensen et al. showed that the propeptide sequence, which is found in the precursors of the vitamin $\mathrm{K}$-dependent proteins, is essential for the carboxylation of recombinant human Factor IX in Chinese hamster ovary cells (3), and Knobloch and Suttie demonstrated that an amino-terminal attached propeptide confers on the substrate a submicromolar $K_{\mathrm{m}}$ for $\gamma$-carboxylase in vitro (4). Even though extensive conservation of sequence is not seen in the propeptide sequences of the vitamin K-dependent proteins, two highly conserved residues, Phe at -16 and Ala at -10 , have been proven critical for carboxylation (Fig. 2 and reference 5). We report here an unusual mechanism of warfarin sensitivity because of a substitution of Thr for Ala at position -10 of the propeptide of human Factor IX. Because the patient was perfectly normal on coagulation screening tests until challenged with warfarin, we studied the biochemical mechanism of this defect. The system we chose is a well-estab-

1. Abbreviations used in this paper: A, adenosine; aPTT, activated partial thromboplastin time; F.VII, F.VIII, F.IX, and F.X, Factors VII, VIII, IX, and X, respectively; G, guanosine; Gla, $\gamma$-carboxyglutamic acid; PT, prothrombin time. 


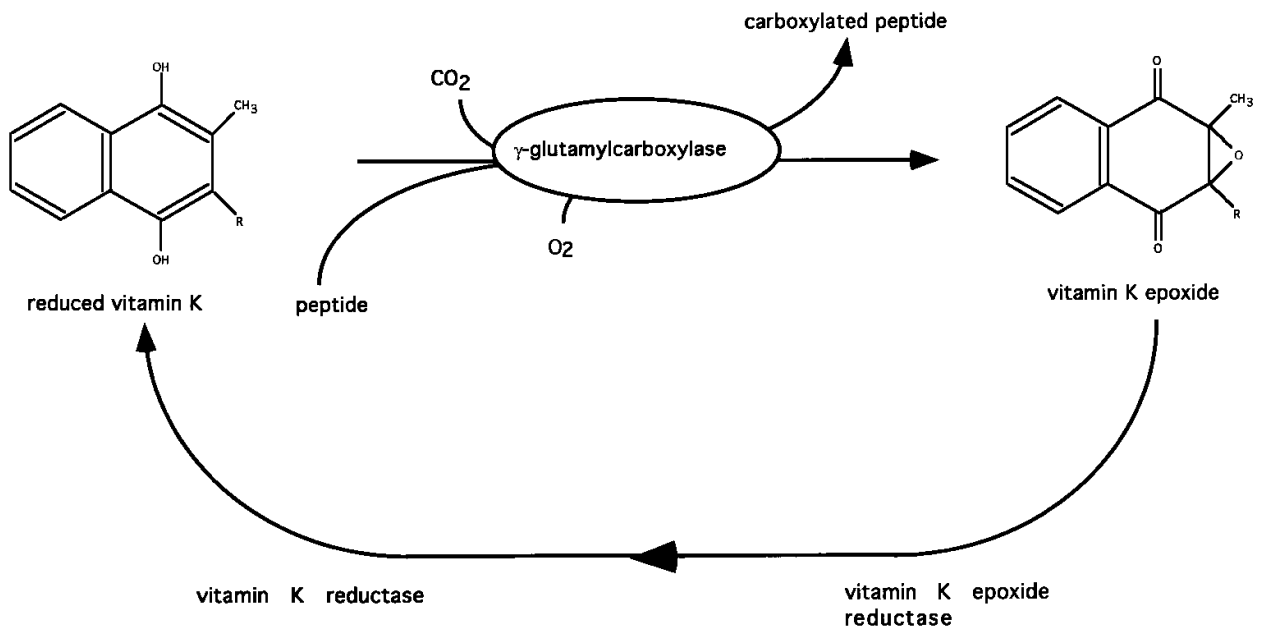

Figure 1. $\gamma$-carboxylation of vitamin $\mathrm{K}$-dependent proteins. The $\gamma$-glutamylcarboxylase requires reduced vitamin $\mathrm{K}, \mathrm{CO}_{2}$, and $\mathrm{O}_{2}$ as cofactors for the carboxylation of vitamin $\mathrm{K}$-dependent proteins. In the reaction, $\gamma$-glutamylcarboxylase catalyzes the oxidation of $1 \mathrm{~mol}$ of reduced vita$\min \mathrm{K}$ to vitamin $\mathrm{K}$ epoxide for each mole of $\mathrm{CO}_{2}$ incorporated into the peptide. lished in vitro $\gamma$-carboxylation assay using substrates containing the mutant propeptide and Gla domain sequences of human Factor IX (6). Using Michaelis-Menten kinetics, we demonstrated that the mutant peptide has a reduced affinity for the carboxylase when compared to the wild-type peptide substrate. This mutation is of interest from a scientific standpoint because, among the vitamin $\mathrm{K}$-dependent clotting factors, it is the first example of a naturally occurring mutation that has a direct effect on $\gamma$-carboxylation. From a clinical standpoint, the study of this mutation has allowed the elucidation of a novel mechanism of warfarin sensitivity.

\section{Methods}

Patient history. The patient is a 49 -yr-old Caucasian male who was referred for evaluation of bleeding complications that developed during anticoagulation with warfarin. The patient's history is significant for a congenital bicuspid aortic valve with accompanying aortic steno-

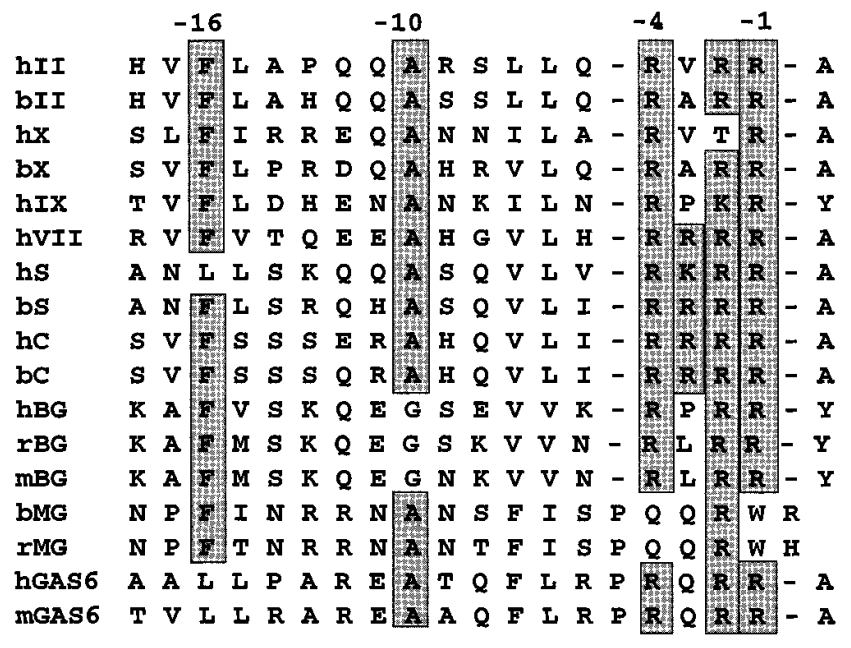

Figure 2. Amino acid sequence alignment of the propeptides of the vitamin $\mathrm{K}$-dependent proteins. Highly conserved residues are shaded in gray. These include, in addition to the basic residues at the $\mathrm{COOH}-$ terminus, alanine at residue -10 and phenylalanine at residue $-16 . h$, human; $b$, bovine; $r$, rat; $m$, mouse; $S$, protein $\mathrm{S} ; C$, protein $\mathrm{C} ; B G$, bone Gla protein; $M G$, bone matrix Gla protein; $G A S 6$, growth arrest-specific protein. sis and regurgitation. At the age of 49 , he developed progressive left ventricular hypertrophy and critical aortic stenosis, and underwent placement of a St. Jude's (tilting disc) valve. Preoperative coagulation screening tests including the prothrombin time (PT) and the activated partial thromboplastin time (aPTT) were within normal limits. The patient's immediate postoperative course was uncomplicated. He was discharged on the fifth postoperative day, with prescribed medications, including warfarin, digoxin, furosemide, metoprolol, ferrous sulfate, and oxycodone. Over the ensuing $2 \mathrm{mo}$, the patient was repeatedly admitted to the hospital for bleeding complications, including a hemothorax, multiple episodes of hematuria, and episodes of ecchymoses over the arms, legs, and trunk. Evaluation of coagulation parameters repeatedly disclosed prolonged coagulation screens (e.g., PT $23.7 \mathrm{~s}$, aPTT $>150 \mathrm{~s}$ ), which corrected on mixing with normal plasma. Factor assays obtained during one of these admissions showed F.VII activity of $42 \%$, F.VIII activity of $>200 \%$, and F.IX activity of $<1 \%$. When warfarin was stopped, screens returned to normal, as did the F.IX activity level (148\%). When warfarin was restarted at a lower dose, the patient's F.IX level again fell to $<1 \%$; on stopping warfarin, the F.IX activity level rose to $120 \%$.

The patient has a history of mild Charcot-Marie-Tooth disease, manifest by muscular atrophy in the left lower extremity. The patient's mother, his maternal grandfather, and two of his three children also have Charcot-Marie-Tooth disease. The patient's family history was negative for bleeding diatheses. His physical examination was positive for a thoracotomy scar on the chest, as well as moderately severe muscle atrophy in the left lower extremity. Cardiac examination was consistent with the presence of a mechanical valve in the aortic position. Medications at the time of evaluation at this hospital included metoprolol $50 \mathrm{mg}$ bid and warfarin $2.5 \mathrm{mg}$ for $3 \mathrm{~d}$, then $5 \mathrm{mg}$ on the 4th d, then restart $2.5 \mathrm{mg}$. Laboratory evaluation on initial presentation at this hospital showed a PT of $11.4 \mathrm{~s}$ (normal range $=11.3-$ $13.1 \mathrm{~s}$ ), an aPTT of $40.7 \mathrm{~s}$ (normal range $=24.0-39.0 \mathrm{~s}$ ), F.VII activity of $80 \%$, F.IX activity of $16 \%$, F.X activity of $43 \%$, and protein C activity of $123 \%$. F.IX antigen level by ELISA was $1.5 \mu \mathrm{g} / \mathrm{ml}$ (normal = $5 \mu \mathrm{g} / \mathrm{ml}$ ). A complete blood count showed a white blood cell count of $6,000 / \mathrm{mm}^{3}$, hemoglobin of $13.7 \mathrm{gm} / \mathrm{dl}$, hematocrit of $41.2 \%$, and a platelet count of $250,000 / \mathrm{mm}^{3}$. After informed consent, peripheral blood was obtained for DNA analysis. The patient has remained free of thrombotic and hemorrhagic complications on the warfarin regimen described.

Antigen and activity assays for coagulation proteins. PT and aPTT were performed by a semiautomated method, using a Coag-A-Mate X2 instrument (Organon-Teknika, Research Triangle Park, NC). Rabbit brain thromboplastin (Simplastin Excel; Organon Teknika) was used as reagent for the PT assay, and rabbit brain phospholipid (Platelin) was used as reagent for the aPTT. Activity assays for Factors VII, IX, and $\mathrm{X}$ were performed on patient plasma diluted into factor-deficient 
plasma using either a PT- (F.VII) or aPTT-based (F.IX and F.X) assay. Protein $\mathrm{C}$ activity was determined using a commercially available chromogenic assay (American Bioproducts, Parsippany, NJ). F.IX antigen level was determined by an ELISA in which a commercially available rabbit anti-human F.IX polyclonal antibody (Dako Corp., Carpinteria, CA) was used as the capture antibody, and a polyclonal goat anti-human F.IX antibody coupled to horseradish peroxidase (Affinity Biologicals, Hamilton, Ontario, Canada) was used as the detecting antibody.

Mutation analysis. Genomic DNA was purified from peripheral blood according to the method of Bell et al. (7). Genomic DNA was amplified by PCR (8). 50- $\mu \mathrm{l}$ reaction mixtures contained $0.1 \mu \mathrm{g}$ of genomic DNA, $0.1 \mu \mathrm{M}$ amplification primers, and $200 \mathrm{mM}$ dNTPs in a buffer of $10 \mathrm{mM}$ Tris, $\mathrm{pH} 8.3,50 \mathrm{mM} \mathrm{KCl}, 2.5 \mathrm{mM} \mathrm{MgCl}_{2}$, and $0.01 \%$ gelatin. Amplification primers previously described (9) were derived from intron sequences such that all exons and intron-exon junctions were amplified. Exons 2 and 3 were amplified together, and the $\sim 1,000$ bp exon 8 was amplified in two fragments. After the addition of $1.5 \mathrm{U}$ of Taq polymerase (Perkin Elmer Corp., Norwalk, CT), the reaction mixtures were overlaid with mineral oil and heated to $94^{\circ} \mathrm{C}$ for 10 min. 30 amplification cycles were performed consisting of $2 \mathrm{~min}$ at $55^{\circ} \mathrm{C}$ (primer annealing); 3 min at $72^{\circ} \mathrm{C}$ (primer extension); and $2 \mathrm{~min}$ at $94^{\circ} \mathrm{C}$ (denaturation). PCR reaction mixtures were subjected to $1 \%$ agarose gel electrophoresis in Tris-borate-EDTA buffer at $95 \mathrm{~V}$. DNA bands were visualized by ethidium bromide staining and excised. DNA was purified from the isolated agarose fragments and resuspended in $8 \mu \mathrm{l}$ of distilled, deionized water for dideoxy sequence analysis. Sequencing reactions were carried out by adding $2 \mu \mathrm{l}$ of $5 \mathrm{X}$ Sequenase (U.S. Biochemical Corp., Cleveland, $\mathrm{OH}$ ) reaction buffer and $0.4 \mu \mathrm{l}$ of $10 \%$ Nonidet P-40 (Sigma Immunochemicals, St. Louis, MO) to resuspended, PCR-amplified DNA fragments and heating them to $100^{\circ} \mathrm{C}$ for $3 \mathrm{~min} .2 \mu \mathrm{l}$ of water were added to the reaction, and dideoxy sequencing reactions were carried out with Sequenase according to the manufacturer's instructions. Termination reactions were separated on a $6 \%$ denaturing polyacrylamide gel at $75 \mathrm{~W}$, and autoradiographs were produced by exposing dried gels to film for 24 $72 \mathrm{~h}$.

Site-directed mutagenesis. cDNAs encoding the substitution of glycine $(\mathrm{A}-10 \mathrm{G})$ and threonine (A-10T) for the normal alanine at position -10 in the human F.IX propeptide were produced by overlapping PCR using Vent polymerase (New England Biolabs, Beverly, MA; reference 10). The threonine substitution is based on the mutation in the patient; the glycine substitution was produced to replicate the homologous residue in bone Gla protein $(11,12)$. The template used was the vector pMa1422, which is derived from pMc292 (6) and directs the expression of a fusion protein of phage T7 gene 10 and a fragment of human F.IX extending from residues -18 through +41 in the mature protein. In the first round of PCR, a 394-bp fragment containing the mutation at the $3^{\prime}$ end and a 189-bp fragment containing the mutation at the $5^{\prime}$ end were amplified. The second round of PCR used a mixture of the first two products (annealed at the site of overlap that includes the desired mutation) as template and the original flanking oligomers. A 583-bp fragment was generated which was digested at internal NcoI and BamHI sites and subcloned into the pMa1422 vector digested with the same enzymes. After subcloning, the mutations were confirmed by DNA sequence analysis.

Expression, purification, and characterization of wild-type and mutant peptides. T7 gene 10 fusion proteins were synthesized as previously described in Escherichia coli (6). Inclusion bodies were isolated from a 4-liter culture. After cyanogen bromide cleavage, the dried peptides were resuspended in $50 \mathrm{ml}$ of $8 \mathrm{M}$ guanidine- $\mathrm{HCl}$. The peptides were sulfonated by the addition of 0.15 gm sodium tetrathionate and $0.3 \mathrm{gm}$ sodium sulfite, $\mathrm{pH}$ was adjusted to 9.0 with ammonium hydroxide, and the reaction was incubated at room temperature for $16 \mathrm{~h}$. The sulfonated peptides were then dialyzed against three changes of $25 \mathrm{mM}$ MOPS $\mathrm{pH} 8.0,10 \mathrm{mM} \mathrm{NaCl}$ to precipitate the gene 10 fragments while the target peptides remained in solution. The gene 10 fragments were removed by centrifugation at $12,000 \mathrm{~g}$ for $15 \mathrm{~min}$.
The supernatant was loaded on a DEAE-Sepharose CL-6B $(5 \mathrm{ml})$ column, and the target peptide was eluted with $250 \mathrm{mM} \mathrm{NaCl}$. Sulfonation was reversed by incubating the eluted peptides at room temperature for $3 \mathrm{~h}$ with $100 \mathrm{mM}$ DTT. The peptides were further purified by reverse-phase HPLC using a widebore C-18 column (300 ̊̊ pore size: Rainin Instrument Co. Inc., Woburn, MA). Peptides were eluted using a linear gradient $(1 \mathrm{ml} / \mathrm{min})$ of $0 \%$ buffer A $(0.1 \%$ trifluoroacetic acid) to $100 \%$ buffer B $(90 \%$ acetonitrile/ $0.1 \%$ trifluoracetic acid) over $10 \mathrm{ml}$. The peptides were dried and resuspended in 10 $\mathrm{mM}$ ammonium hydroxide.

Confirmation of peptide molecular weight by electrospray ionization mass spectroscopy. The molecular mass of each peptide was determined using a VG Quattro BQ triple quadropole mass spectrometer (Fisons Instruments, Inc., Danvers, MA) equipped with a pneumatically assisted electrostatic ion source operating at atmospheric pressure. Samples were reconstituted in $50 \%$ aqueous acetonitrile containing formic acid $(1 \% \mathrm{vol} / \mathrm{vol})$, and were introduced by loop injection into a stream of $50 \%$ aqueous acetonitrile flowing at $6 \mu \mathrm{l} / \mathrm{min}$. Mass spectra were acquired in the multichannel analyzer (MCA) mode from mass-to-charge $(\mathrm{m} / \mathrm{e}) 700-1400$ with a scan time of $10 \mathrm{~s}$. The mass scale was calibrated with horse heart myoglobin $\left(M_{\mathrm{r}}=\right.$ 16951.48) with a resolution corresponding to a peak width half height of $1.0 \mathrm{D}$ for $\mathrm{m} / \mathrm{e} 893$. The mass spectra were transformed to a molecular mass scale using software supplied by the manufacturer

Peptide kinetics assay. In this assay, washed bovine liver microsomes, which serve as a source of $\gamma$-glutamylcarboxylase, are incubated with reduced vitamin $\mathrm{K}$ and $\mathrm{NaH}^{14} \mathrm{CO}_{3}$ as a source of labeled $\mathrm{CO}_{2}$. Reactions are initiated by the addition of the peptide substrates, and progress of the reaction is monitored by measuring the incorporation of ${ }^{14} \mathrm{CO}_{2}$ into peptides. Microsomes and vitamin $\mathrm{K}$ hydroquinone were prepared as previously described (6). All kinetic assays were done in a total volume of $125 \mu \mathrm{l}$ using $1 \mathrm{mg}$ of microsomal proteins in $25 \mathrm{mM}$ Mops, pH 7.4, 0.5 M NaCl, 0.4\%, 3-[(3-cholamidopropyl)-dimethylammonio]-1-propane sulfonate (CHAPS) $222 \mu \mathrm{M}$ vitamin $\mathrm{K}$ hydroquinone, $6 \mathrm{mM}$ DTT, $5 \mu \mathrm{Ci} \mathrm{NaH}{ }^{14} \mathrm{CO}_{3}$ (specific activity $=$ $54 \mathrm{mCi} / \mathrm{mmol}$ ), and the appropriate amount of the peptide substrate. For kinetics assays, the microsomes were presolubilized with $1 \%$ CHAPS on ice for $10 \mathrm{~min}$ with $125 \mathrm{mM}$ Mops, $\mathrm{pH} 7.4$, and $1 \mathrm{M} \mathrm{NaCl}$. The vitamin $\mathrm{K}$ hydroquinone and $\mathrm{NaH}^{14} \mathrm{CO}_{3}$ were then added for a 3 -min preincubation at $25^{\circ} \mathrm{C}$. The reaction was initiated by adding the preincubated reaction mixture to dilutions of the peptide (wild-type, 0-12 $\mu \mathrm{M}$; mutant peptides, $0-60 \mu \mathrm{M}$ ). The final concentrations of the peptides used in the kinetic studies were determined by amino acid analysis using aminobutyric acid as an internal standard. The reaction was allowed to proceed at $25^{\circ} \mathrm{C}$ for $10 \mathrm{~min}$, at which point the reaction was quenched by the addition of $75 \mu \mathrm{l} 1 \mathrm{~N} \mathrm{NaOH}$. The samples were then acidified with $1 \mathrm{ml}$ of $5 \%$ TCA, and were boiled for $10 \mathrm{~min}$ to remove unincorporated ${ }^{14} \mathrm{CO}_{2}$. The incorporation of ${ }^{14} \mathrm{CO}_{2}$ was determined by scintillation counting. In our experience, human wild-type substrates are efficiently carboxylated by bovine microsomes, so interspecies variations do not impede the assay.

Vitamin K kinetics assay. The reaction conditions were identical to those used in the peptide kinetics experiments, except that reactions were initiated by the addition of vitamin $\mathrm{K}$ hydroquinone $(0-222 \mu \mathrm{M})$, and the peptide concentrations were $0.3 \mu \mathrm{M}$ for the wild-type peptide and $10 \mu \mathrm{M}$ for the mutant peptides. Additional experiments were performed at peptide concentrations of approximately five times the $K_{\mathrm{m}}(1$ and $50 \mu \mathrm{M}$, respectively).

Data analysis. Kinetic parameters were determined using nonlinear least squares analysis and fitting the data to the MichaelisMenten equation. All reported kinetic values are averages of at least two independent assays.

\section{Results}

Warfarin sensitivity results from a profound drop in F.IX activity levels in response to warfarin therapy. The patient's F.IX 


\section{NORMAL PATIENT}

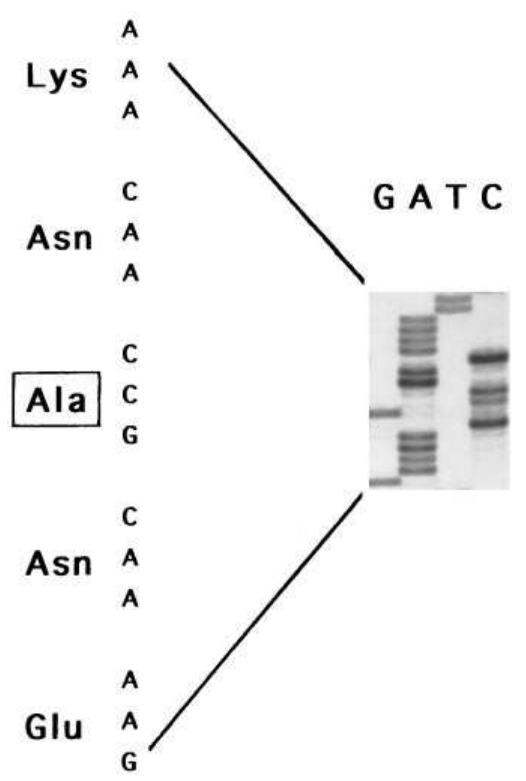

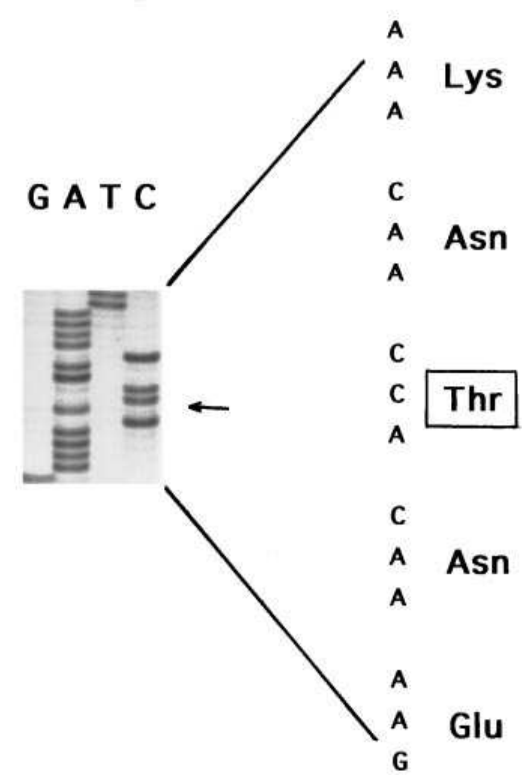

Figure 3. Nucleotide sequence of exon 2 of amplified genomic DNA from normal control and from variant F.IX. A $\mathrm{G} \rightarrow \mathrm{A}$ transition at the first nucleotide of codon -10 (nucleotide 6346 [13]) changes alanine to threonine in the propeptide of F.IX. activity level is within normal limits $(148 \%, 120 \%)$ when the patient is not ingesting warfarin. This is entirely consistent with the absence of any bleeding history before the initiation of warfarin therapy. During the first 4 mo of therapy with warfarin, it was repeatedly documented that usual doses of the drug, sufficient to prolong the PT into the therapeutic range, were associated with a dramatic reduction in the patient's F.IX activity level, to $<1 \%$, at a time when the other vitamin $\mathrm{K}$-dependent clotting factors were only moderately reduced. When referred for evaluation, the patient was on a lower dose of warfarin (not sufficient to prolong the PT), but the sensitivity of the F.IX level to warfarin was still evident, with a F.IX activity level of $16 \%$ at a time when F.VII and F.X levels were 80 and $43 \%$, respectively. The F.IX antigen level by ELISA was $30 \%$.

Mutation analysis discloses a missense mutation in exon 2 of the F.IX gene. Direct sequence analysis of amplified genomic DNA from all eight exons and from the exon-intron junctions of the F.IX gene demonstrated a single difference from the wild-type sequence, a guanosine $\rightarrow$ adenosine $(\mathrm{G} \rightarrow \mathrm{A})$ transition at nucleotide 6346 (numbering according to Yoshitake et al. (13)) in exon 2 (Fig. 3). The mutation was confirmed by sequence analysis of the opposite strand and by sequence analysis of three independent PCR amplification products. This single nucleotide change results in the substitution of threonine for alanine at residue -10 in the propeptide.

The mutant propeptide has a reduced affinity for the carboxylase. Previous work has shown that a 59-amino acid peptide spanning residues -18 to +41 of the F.IX protein is an excellent substrate for $\gamma$-glutamylcarboxylase, with an apparent $K_{\mathrm{m}}$ in the micromolar range (6). Peptides that were analyzed in this study included the wild-type sequence, the A-10T sequence, and an A-10G sequence, a substitution based on the sequence in bone matrix Gla protein $(11,12)$. The molecular weights of the peptides were confirmed by electrospray ionization mass spectroscopy. Experimentally determined molecular weights $(7052.22 \pm 0.61,7081.61 \pm 0.28$, and $7038.45 \pm 0.41$ for wild-type, A-10T, and A-10G, respectively) were in close agreement with predicted values for these peptides (7052, 7082 , and 7038). The $K_{\mathrm{m}}$ was determined for the wild-type sub-

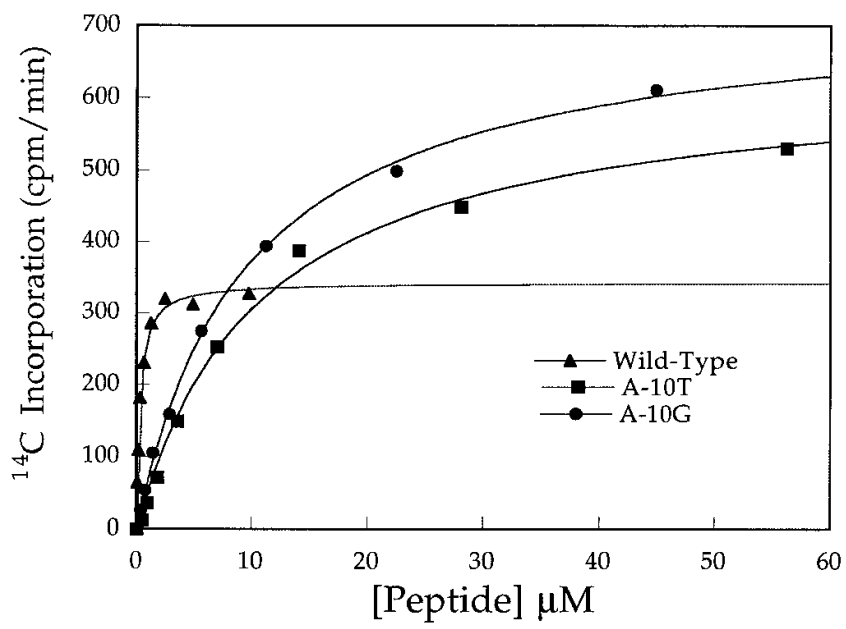

Figure 4. Kinetic analysis of the $\gamma$-carboxylation of F.IX peptides. The affinity of the carboxylase complex ( $\gamma$-glutamylcarboxylase and reduced vitamin $\mathrm{K}$ ) for a peptide containing the normal propeptide and Gla domain sequence of F.IX and two variant peptides containing the propeptide sequences found in the patient (A-10T) and in bone Gla protein (A-10G) are determined by the addition of varying concentrations of the peptides. The wild-type peptide has a higher affinity for $\gamma$-glutamylcarboxylase $\left(K_{\mathrm{m}}=0.29 \pm 0.02 \mu \mathrm{M}\right)$ than A-10T $\left(K_{\mathrm{m}}=10.9 \pm 1.2 \mu \mathrm{M}\right)$ and A-10G $\left(K_{\mathrm{m}}=9.5 \pm 1.7 \mu \mathrm{M}\right)$. Maximal velocities $\left(V_{\max }\right)$ for the variant peptides are approximately equivalent $\left(638 \pm 32 \mathrm{cpm} \cdot \mathrm{min}^{-1}\right.$ for A-10T, and $726 \pm 56 \mathrm{cpm} \cdot \mathrm{min}^{-1}$ for A-10G), and are only twofold higher than $V_{\max }$ for the wild-type peptide $\left(343 \pm 21 \mathrm{cpm} \cdot \mathrm{min}^{-1}\right)$. Vitamin $\mathrm{K}$ concentration was $222 \mu \mathrm{M}$ for all three reactions. 
Table I. Kinetics of IX -18 to +41 Peptides in Microsomes Peptide Kinetics

\begin{tabular}{lccccc}
\hline Peptide & $K_{\mathrm{m}}$ & Error* & $V_{\max }$ & Error & $V_{\max } / K_{\mathrm{m}}$ \\
\hline & $\mu M$ & & $c p m /$ min & & $\mathrm{cpm} / \mathrm{min} \cdot \mu M$ \\
Wildtype & 0.29 & 0.02 & 343 & 21 & 1180 \\
A-10T & 10.9 & 1.20 & 638 & 32 & 58.5 \\
A-10G & 9.50 & 1.70 & 726 & 56 & 76.4 \\
& & & & &
\end{tabular}

*For Tables I and II, each determination was done at least twice; error is defined as standard error of the mean for averaged values.

strate $(0.29 \mu \mathrm{M})$ and for the variants $(10.90$ and $9.50 \mu \mathrm{M}$, respectively, for A-10T and A-10G) (Fig. 4 and Table I). The $V_{\max }$ values are roughly equivalent; $V_{\max }$ of the variant substrates is only twofold higher than that for the wild-type. Thus, the major difference between the variant and wild-type peptides as substrates for the $\gamma$-glutamylcarboxylase is in the $K_{\mathrm{m}}$, indicating that the mutant peptides have a more than 30 -fold lower affinity for the carboxylase.

The mutation in the propeptide does not alter the affinity of the enzyme-peptide complex for reduced vitamin $K$. In the conversion of peptide substrates to carboxylated products by $\gamma$-glutamylcarboxylase, reduced vitamin $\mathrm{K}$ is converted to vitamin $\mathrm{K} 2$, 3-epoxide as part of the reaction. In this sense, vitamin $\mathrm{K}$ can be regarded as the substrate of the carboxylase, in which case the enzyme could be called vitamin $\mathrm{K}$ epoxidase. Previous work (14) has demonstrated that there is 1:1 stoichiometry between incorporation of $\mathrm{CO}_{2}$ into a peptide substrate and oxidation of vitamin $\mathrm{K}$. Therefore, vitamin $\mathrm{K}$ kinetics can

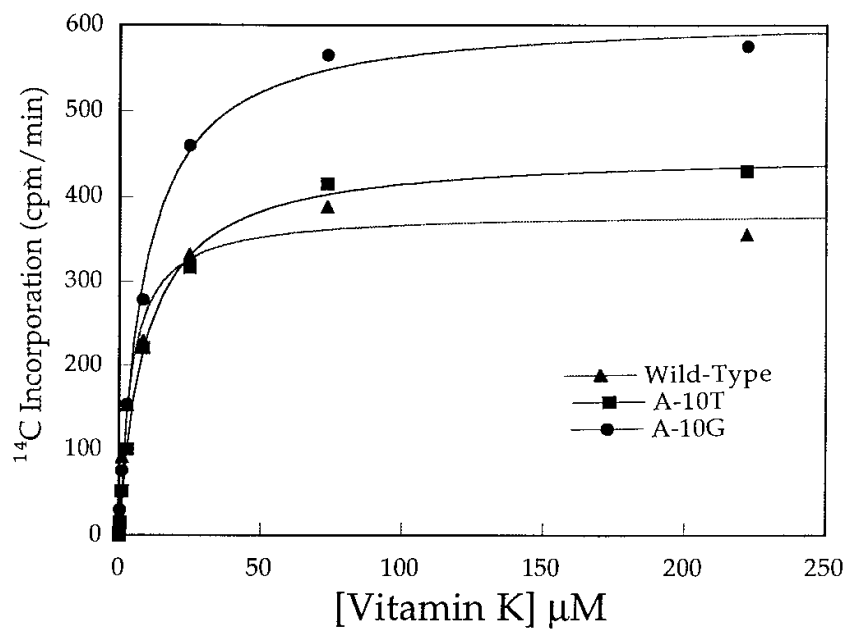

Figure 5. Kinetic analysis of reduced vitamin $\mathrm{K}$ in $\gamma$-carboxylation of F.IX peptides. The affinity of the carboxylase complex ( $\gamma$-glutamylcarboxylase and F.IX peptides) for vitamin $\mathrm{K}$ is determined by the addition of varying concentrations of reduced vitamin $\mathrm{K}$ to initiate the carboxylation reaction. The $K_{\mathrm{m}}$ of the complex containing the wild-type peptide is $4.2 \pm 0.24 \mu \mathrm{M}$; the complexes containing the variant peptides have only a twofold lower affinity for vitamin $\mathrm{K}\left(K_{\mathrm{m}}=\right.$ $9.3 \pm 1.5$ for the complex containing the A-10T peptide and $8.6 \pm 0.20$ for the A-10G peptide). The $V_{\max }$ for each complex is similar $\left(383 \pm 21,454 \pm 15,612 \pm 36 \mathrm{cpm} \cdot \mathrm{min}^{-1}\right.$ for wild-type, A-10T, and A-10G, respectively).
Table II. Kinetics of IX -18 to +41 Peptides in Microsomes Vitamin K Kinetics

\begin{tabular}{lccccc}
\hline Peptide & $K_{\mathrm{m}}$ & Error & $V_{\max }{ }^{*}$ & Error & $V_{\max } / K_{\mathrm{m}}$ \\
\hline & $\mu M$ & & $\mathrm{cpm} / \mathrm{min}$ & & $\mathrm{cpm} / \mathrm{min} \cdot \mu M$ \\
Wildtype & 4.2 & 0.24 & 383 & 21 & 91.2 \\
A-10T & 9.3 & 1.50 & 454 & 15 & 48.8 \\
A-10G & 8.6 & 0.20 & 612 & 36 & 71.2 \\
& & & & & \\
\hline
\end{tabular}

*Maximal rate at $0.3 \mu \mathrm{M}$ wild-type peptide and $10 \mu \mathrm{M}$ A-10T or A-10G.

be monitored by following $\mathrm{CO}_{2}$ incorporation into the peptide substrates. The reactions are carried out in a fashion similar to those described above, except that the peptides are added to the preincubation, and reactions are initiated by adding reduced vitamin K. The results shown in Fig. 5 and Table II were carried out at peptide concentrations near the $K_{\mathrm{m}}(0.3 \mu \mathrm{M}$ for wild-type, $10 \mu \mathrm{M}$ for mutant peptides), and demonstrate only a modest difference in $V_{\max }$ between the complex formed with the wild-type peptide and those formed with the variant peptides. In particular, the $V_{\max }$ for wild-type and A-10T are similar, and that for A-10G is $\sim 1.6$ times that of wild-type. There is a twofold increase in $K_{\mathrm{m}}$ for the variant peptides compared to wild-type. These $K_{\mathrm{m}}$ values were confirmed in additional experiments carried out at higher peptide concentrations $(1 \mu \mathrm{M}$ for wild-type, $50 \mu \mathrm{M}$ for mutant peptides). Thus, both enzyme-peptide complexes containing variant peptides have lower affinities for vitamin $\mathrm{K}$ than the complex containing the wild-type peptide, but the difference is not marked.

\section{Discussion}

In this report, we describe the first naturally occurring mutation in a vitamin $\mathrm{K}$-dependent clotting factor that directly affects carboxylation by the $\gamma$-glutamylcarboxylase; the object of the studies in the report is to determine how the mutation affects carboxylation and leads to a syndrome of warfarin sensitivity.

With no antecedent history of a bleeding diathesis, this patient was repeatedly hospitalized with bleeding complications on warfarin at a time when the PT was in the therapeutic range. Preoperative coagulation screens had been within normal limits, but during warfarin treatment, the patient's F.IX activity fell to $<1 \%$ while the F.VII level was $42 \%$. Off warfarin, the F.IX level rose to $>100 \%$ (documented on more than one occasion), ruling out undiagnosed hemophilia B as the cause of the patient's difficulties. Direct sequencing of amplified genomic DNA from the patient's F.IX gene disclosed a single-point mutation that results in the substitution of threonine for alanine at position -10 in the pre-pro leader sequence. This mutation falls within the propeptide sequence, which has been shown to be the essential recognition element for carboxylation (3). The most highly conserved residues within the propeptide (Fig. 2) are a phenylalanine at position -16 and an alanine at position -10 . An alanine is found at position -10 in all the known vitamin $\mathrm{K}$-dependent proteins except bone Gla protein, where a glycine is present at -10 .

There are no previous reports of naturally occurring mutations at position $-10(15)$, but the importance of this residue 
has been demonstrated by Rabiet et al., who showed that substitution of glutamic acid for alanine (a nonconservative change) in a recombinant F.IX variant resulted in a species that was poorly carboxylated in $\mathrm{CHO}$ cells, with $<2$ mol of $\mathrm{Gla} / \mathrm{mol}$ protein, compared to an expected content of $12 \mathrm{~mol}$ $\mathrm{Gla} / \mathrm{mol}$ protein (5). Cheung et al. have also examined the affinity of chemically synthesized F.X propeptides for the carboxylase by determining their ability to stimulate carboxylation of the pentapeptide substrate FLEEL in vitro. In these experiments, the substitution of glutamic acid or valine for alanine -10 resulted in no detectable binding to carboxylase (16).

To understand the defect reported here at the molecular level, we used a well-characterized system for constructing peptides and assaying their kinetic properties toward the carboxylase (6). The peptides, synthesized in a bacterial expression system, consist of the wild-type or mutant propeptide covalently linked to the Gla domain of F.IX. Studies by a number of groups $(4,14,17,18)$ have shown that attaching the propeptide to the substrate lowers the apparent $K_{\mathrm{m}}$ of reduced vitamin $\mathrm{K}$ for the carboxylase. Thus, for example, when the pentapeptide FLEEL is the substrate, the apparent $K_{\mathrm{m}}$ for reduced vitamin $\mathrm{K}$ is $\sim 100 \mu \mathrm{M}$, but a 59 -amino acid sequence spanning the region from -18 to +41 of the human F.IX protein has a $K_{\mathrm{m}}$ app 100-fold lower ( $\sim 1 \mu \mathrm{M}$; reference 18). Based on these data, we initially hypothesized that a mutation in the propeptide sequence would result in a higher apparent $K_{\mathrm{m}}$ of the peptide-enzyme complex for reduced vitamin K. Since warfarin treatment results in a marked decrease in the levels of reduced vitamin $\mathrm{K}$, it is a reasonable prediction that the mutation would thus result in markedly decreased levels of F.IX activity in the presence of warfarin. This hypothesis, however, is not supported by the in vitro kinetic studies, which show that the major difference between wild-type and variant peptides is the 30 -fold increase in the apparent $K_{\mathrm{m}}$ of the variant peptide to the carboxylase compared to the wild-type peptide. The $K_{\mathrm{m}}$ of the enzyme-variant peptide complex for reduced vitamin $\mathrm{K}$ was only approximately twofold higher than that of the enzyme-wild-type complex, so that the mutation does not result in markedly altered affinity of the complex for vitamin K. Instead the data show that a propeptide containing threonine at position -10 is a poor substrate for carboxylase compared to one with alanine at position -10 . Although one must always be cautious in extrapolating results from in vitro studies to the in vivo setting, it seems likely that the low affinity of the carboxylase for the mutant propeptide is the difference that accounts for the dramatic reduction in F.IX levels on warfarin.

This observation in turn, however, raises the question of why the patient has normal levels of F.IX in the absence of warfarin. We propose the following explanation. As originally pointed out by Segel (19), the $K_{\mathrm{m}}$ establishes an approximate value for the concentration of a substrate in vivo. This allows for maximal responsiveness of the reaction rate to changes in substrate concentration. Thus, in the absence of warfarin, the concentration of the mutant F.IX precursor may be 30 -fold higher than that of the wild-type substrate. This accumulation of the precursor allows for the synthesis of normal levels of fully processed F.IX despite its reduced affinity for the carboxylase. In the presence of warfarin, however, the precursors of all the vitamin $\mathrm{K}$-dependent proteins begin to accumulate (20). When all of the substrates are present at increased concentrations, the reduced affinity of the carboxylase for the mutant F.IX substrate results in a marked decrease in carboxyla- tion of the mutant F.IX. This interpretation can be expressed mathematically by an equation that gives relative reaction velocities for two competing substrates (21):

$v_{\text {mutant }}$ F.IX $/ v_{\mathrm{wt}}=\left(k_{\mathrm{cat}} / K_{\mathrm{m}}\right)_{\text {mutant }}[$ mutant F.IX $] /\left(k_{\mathrm{cat}} / K_{\mathrm{m}}\right)_{\mathrm{wt}}[w t]$

In the absence of warfarin, the intracellular concentrations of both substrates are approximately equal to their respective $K_{\mathrm{m}}$ values, and the two terms cancel out so that the relative rates are only dependent on the relative $k_{\text {cat }}$ values. Since $k_{\text {cat }}$ is proportional to $V_{\max }$, the F.IX levels are similar and within the normal range. In the presence of warfarin, however, the concentrations of all substrates rise 10-20-fold (20); the concentration of F.IX, already near maximum, cannot rise further, and the carboxylation of the precursors of the other vitamin $\mathrm{K}$-dependent factors outcompetes the mutant F.IX precursors.

The low affinity of the carboxylase for the mutant propeptide may contribute to the low levels of active F.IX by another mechanism. Morris et al. (22) have demonstrated that the $\gamma$-glutamylcarboxylase is a processive enzyme such that multiple carboxylations occur in a single enzyme-substrate association. Warfarin inhibits the regeneration of vitamin K hydroquinone and thus reduces its availability for the reaction; this slows the process of carboxylation. Therefore, if the amount of time the substrate remains bound to the carboxylase is reduced by the lower affinity of the mutant propeptide, premature dissociation of the enzyme-substrate complex may result in incomplete carboxylation. This effect may account in part for the pronounced reduction in F.IX activity compared to the other vitamin $\mathrm{K}$-dependent proteins, and may also explain the discrepancy between the F.IX antigen and activity levels in this patient (30\% antigen, 16\% activity when both were measured simultaneously). It should be noted, however, that such a discrepancy is routinely seen in patients on warfarin (23) and thus can be accounted for without invoking the presence of the propeptide mutation.

It is of note that the A-10G substitution, based on the residue found in bone Gla protein, also results in a 30-fold reduced affinity for the carboxylase and virtually no change in affinity for reduced vitamin K. This finding was somewhat surprising, since the change is a conservative one. The weight of the evidence begins to suggest that alanine is uniquely required at position -10 for efficient binding to the carboxylase. Fairly conservative changes such as Ala $\rightarrow$ Gly or Thr (this work) or Val (16), as well as less conservative changes such as Glu or Asp $(5,16)$, appear to have a very significant influence on binding affinity. The kinetic studies with the A-10G substitution also provide an explanation for the observation made a number of years ago that bone Gla protein is more sensitive to warfarin than to coagulation proteins. Price and Kaneda documented in a rat model of warfarin treatment that bone Gla protein is reduced to $5 \%$ of normal at a point when the activity of coagulation proteins is unaffected (12). These investigators proposed that this difference might reflect a difference in vitamin K metabolism in hepatocytes vs. osteoblasts. Our data suggest that the difference is caused by a reduced affinity of the bone Gla precursor for the carboxylase in a manner analogous to the Ala $\rightarrow$ Thr mutation in F.IX. This finding is important, since it challenges the longstanding but poorly documented assumption that all naturally occurring peptide substrates have similar affinities for the carboxylase. Additional support for the notion that affinities differ among substrates is provided in a recent preliminary report by Gillis et al., in which the $K_{\mathrm{m}}$ val- 
ues of the Gas6 and protein S propeptides for the carboxylase were reported to be $\sim 100$ and 400-fold higher, respectively, than the $K_{\mathrm{m}}$ for a prothrombin substrate (24).

This naturally occurring mutation is of considerable interest because it represents a novel mechanism of warfarin sensitivity. Other causes of warfarin sensitivity, including liver disease, vitamin K deficiency, drug interactions, or hyper-metabolic states are associated with prolongation of the PT, and were excluded in this patient. We have recently become aware of another patient with a similar presentation, i.e., normal F.IX levels off warfarin and marked reduction of F.IX activity levels on warfarin, at a time when activity levels of other vitamin $\mathrm{K}$-dependent factors are more modestly reduced (J.A. Humphries, personal communication). This patient also has a mutation in the propeptide of F.IX at a residue (position -9 ) adjacent to the one described in the current report (Chu, K., and K.A. High, unpublished observation). Thus the mechanism of warfarin sensitivity that we describe here may account for other unexplained cases of hyperresponsiveness to the drug. It should be noted that a clue to the underlying pathophysiology in these cases is the markedly prolonged aPTT in the face of a therapeutic PT. Propeptide mutations in other vitamin $\mathrm{K}$-dependent clotting factors would be less likely to cause warfarin sensitivity, since these genes are located on autosomes, and it would be necessary to have the mutation present on both alleles to observe the effect. Similarly, the syndrome of warfarin sensitivity caused by F.IX propeptide mutations should be observed primarily in males.

It is interesting that this mutation is phenotypically silent except when the patient is undergoing therapy with warfarin. This is reminiscent of the data reported for certain mice created by "knockout" technology, where the effects of gene inactivation are not apparent unless the organism is stressed (25). These examples make it clear that it may be difficult or impossible to judge the role of a specific protein (or of a particular residue within a protein) in homeostasis in the undisturbed state.

In summary, we have carried out a series of in vitro carboxylation studies on peptide substrates designed to mimic a naturally occurring propeptide mutation and a change found in bone Gla protein. These studies document the first example of a naturally occurring mutation in a vitamin $\mathrm{K}$-dependent protein that has a direct effect on the efficiency of carboxylation. The studies elucidate a novel mechanism of warfarin sensitivity, and also suggest that the longstanding assumption that all the propeptides have similar affinity for the carboxylase may be incorrect.

\section{Acknowledgments}

This work was supported by National Institutes of Health grants HL48322 to K.A. High and HL-48318 to D.W. Stafford.

\section{References}

1. Stitt, T.N., G. Conn, M. Gore, C. Lai, J. Bruno, C. Radziejewski, K. Mattsson, J. Fisher, D.R. Gies, P.F. Jones et al. 1995. The anticoagulation factor protein S and its relative, Gas6 are ligands for the Tyro 3/Axl family of receptor tyrosine kinases. Cell. 80:661-670.

2. Suttie, J.W. 1993. Synthesis of vitamin K-dependent proteins. FASEB J. $7: 445-452$.

3. Jorgensen, M.J., A.B. Cantor, B.C. Furie, C.L. Brown, C.B. Shoemaker, and B. Furie. 1987. Recognition site directing vitamin K-dependent $\gamma$-carboxylation resides on the propeptide of factor IX. Cell. 48:185-191.

4. Knobloch, J.E., and J.W. Suttie. 1987. Vitamin K-dependent carboxylase. Control of enzyme activity by the "propeptide" region of factor X. J. Biol. Chem. 262:15334-15337.

5. Rabiet, M.J., M.J. Jorgensen, B. Furie, and B.C. Furie. 1987. Effect of propeptide mutations on post-translational processing of factor IX. J. Biol. Chem. 262:14895-14898.

6. Wu, S.-M., B.A.M. Soute, C. Vermeer, and D.W. Stafford. 1990. In vitro gamma-carboxylation of a 59-residue recombinant peptide including the propeptide and the gamma-carboxyglutamic acid domain of coagulation factor IX. Effect of mutations near the propeptide cleavage site. J. Biol. Chem. 265: 13124-13129.

7. Bell, G.I., J.H. Karam, and W.J. Rutter. 1981. Polymorphic DNA region adjacent to the $5^{\prime}$ end of the human insulin gene. Proc. Natl. Acad. Sci. USA. 78 : 5759-5763.

8. Saiki, R.K., D.H. Gelfland, S. Stoffel, S.J. Scharf, R. Higuchi, G.T. Horn, K.B. Mullis, and H.A. Erlich. 1988. Primer-directed enzymatic amplification of DNA with a thermostable DNA polymerase. Science (Wash. DC). 239:487-491.

9. Lozier, J.N., D.M. Monroe, S. Stanfield-Oakley, S.-W. Lin, K.J. Smith, H.R. Roberts, and K.A. High. 1990. Factor IX New London: substitution of proline for glutamine at position 50 causes severe hemophilia. Blood. 75:10971104.

10. Horton, R.M., H.D. Hunt, S.N. Ho, J.K. Pullen, and L.R. Pease. 1989. Engineering hybrid genes without the use of restriction enzymes: gene splicing by overlap extension. Gene (Amst.). 77:61-69.

11. Pan, L.C., and P.A. Price. 1985. The propeptide of rat bone gamma-carboxyglutamic acid protein shares homology with other vitamin K-dependent protein precursors. Proc. Natl. Acad. Sci. USA. 82:6109-6113.

12. Price, P.A., and Y. Kaneda. 1987. Vitamin K counteracts the effect of warfarin in liver but not in bone. Thrombosis Res. 46:121-131.

13. Yoshitake, S., B.G. Schach, D.C. Foster, E.W. Davie, and K. Kurachi 1985. Nucleotide sequence of the gene for human factor IX (antihemophilic factor B). Biochemistry. 24:3736-3750.

14. Morris, D.P., B.A.M. Soute, C. Vermeer, and D.W. Stafford. 1993. Characterization of the purified vitamin K-dependent $\gamma$-glutamyl carboxylase. J. Biol. Chem. 268:8735-8742.

15. Giannelli, F., P.M. Green, S.S. Sommer, M.C. Poon, M. Ludwig, R. Schwaab, P.H. Reitsma, M. Goossens, A. Yoshioka, and G.G. Brownlee. 1996. Haemophilia B (sixth edition): a database of point mutations and short additions and deletions. Nucleic Acids Res. 24:103-118.

16. Cheung, A., J.W. Suttie, and M. Bernatowicz. 1990. Vitamin K-dependent carboxylase: structural requirements for propeptide activation. Biochimica et Biophysica Acta. 1039:90-93.

17. Soute, B.A., M.M. Ulrich, and C. Vermeer. 1987. Vitamin K-dependent carboxylase: increased efficiency of the carboxylation reaction. Thrombosis \& Haemostasis. 57:77-81.

18. Soute, B.A.M., M.M.W. Ulrich, A.D.J. Watson, J.E. Maddison, R.H.M. Ebberink, and C. Vermeer. 1992. Congenital deficiency of all vitamin K-dependent blood coagulation factors due to a defective vitamin K-dependent carboxylase in Devon rex cats. Thrombosis Haemostasis. 68:521-525.

19. Segel, I.H. 1975. Enzyme Kinetics. John Wiley and Sons, Inc., New York. p. 34.

20. de Boer-van den Berg, M.A.G., M.M.W. Ulrich, H.C. Hemker, B.A.M Soute, and C. Vermeer. 1985. Vitamin K-dependent carboxylase: the carboxylation of exogenous substrates in different systems. Biochim. Biophys. Acta. 831:94-98.

21. Fehrst, A. 1985. Enzyme kinetics. In Enzyme Structure and Mechanisms. W.H. Freeman and Company, New York. p. 112.

22. Morris, D.P., R.D. Stevens, D.J. Wright, and D.W. Stafford. 1995. Processive post-translational modification. J. Biol. Chem. 270:30491-30498.

23. Thompson, A.R. 1977. Factor IX antigen by radioimmunoassay. J. Clin. Invest. 59:900-910.

24. Gillis, S., M. Jacobs, B. Furie, and B.C. Furie. 1995. Properties of the propeptide of Gas6. Blood. 86:79a.

25. Frenette, P.S., T.N. Mayadas, H. Rayburn, R.O. Hynes, and D.D. Wagner. 1996. Susceptibility to infection and altered hematopoiesis in mice deficient in both P- and E-selectins. Cell. 84:563-574. 